\title{
Impact of area regeneration policies: performing integral interventions, changing opportunity structures and reducing health inequalities
}

\author{
Angel R Zapata Moya, ${ }^{1}$ Clemente J Navarro Yáñez ${ }^{2}$
}

\begin{abstract}
- Additional material is published online only. To view please visit the journal online (http://dx.doi.org/10.1136/jech2015-207080).

${ }^{1}$ Department of Social Anthropology, Basic Psychology and Public Health, Centre for Urban Political Sociology and Policies, Universidad Pablo de Olavide, Seville, Spain ${ }^{2}$ Department of Sociology, Centre for Urban Political Sociology and Policies, Universidad Pablo de Olavide, Seville, Spain
\end{abstract}

\section{Correspondence to} Angel R Zapata Moya, Centre for Urban Political Sociology and Policies, Department of Social Anthropology, Basic Psychology and Public Health, Building 14-1-34, Universidad Pablo de Olavide, Seville-Spain; arzapmoy@upo.es

Received 9 December 2015 Revised 17 June 2016 Accepted 27 July 2016 Published Online First 24 August 2016
ABSTRACT

Background Urban regeneration policies are areabased interventions addressing multidimensional problems. In this study, we analyse the impact of urban regeneration processes on the evolution of inequalities in mortality from certain causes. On the basis of Fundamental Cause Theory (FCT), our main hypothesis is that the impact of urban regeneration programmes will be more clearly observed on the causes of preventable deaths, as these programmes imply a direct or indirect improvement to a whole range of 'flexible resources' that residents in relevant areas have access to, and which ultimately may influence the inverse relationship between socioeconomic status and health.

Methods Using a quasi-experimental design and data from Longitudinal Statistics on Survival and Longevity of Andalusia (Spain), we analyse differences in the evolution of standard mortality ratios for preventable and less-preventable causes of premature death. This encompasses 59 neighbourhoods in 37 municipalities where urban regeneration projects were implemented in the last decade within the framework of three different programmes and in 59 counterparts where these policies were not implemented.

Results As expected in line with FCT, there are no significant patterns in the evolution of internal differences in terms of less-preventable mortality. However, excessive preventable mortality strongly decreases in the neighbourhoods with intervention programmes, specifically in those where two or more projects were in force. This is even more apparent for women.

Conclusions The urban regeneration policies studied seem to contribute to reducing health inequity when the interventions are more integral in nature.

\section{INTRODUCTION}

Urban regeneration projects are among the most widely used community intervention measures aimed at reducing urban socioeconomic imbalances. They essentially imply a comprehensive process, encompassing a combination of projects to improve the economic, physical, social and environmental conditions in deprived areas. ${ }^{12}$ One of their main objectives is to promote more equality in living conditions among neighbourhoods in cities. ${ }^{3}$ Integral action combining interventions in different policy areas is generally the basic assumption behind their aims, because the problems of a neighbourhood are understood as having multidimensional causes (exclusion processes, housing conditions and urban environments). ${ }^{45}$
Neighbourhoods have been conceptualised as opportunity structures, ${ }^{6}$ a concept that includes the role of individuals as active agents. Neighbourhoods are meant to be pools of resources for living and health; they constitute spatially defined distribution networks through which resources are accessible for improving health. Therefore, as relational spaces linked to where people live, work and play, they contribute to the local production of health inequalities in everyday life. ${ }^{7}$ Given that urban regeneration processes imply a whole range of neighbourhood interventions, they may produce direct and indirect effects on people's health. ${ }^{8} 2$ These effects may primarily result from health-specific actions, such as prevention campaigns, health education/promotion programmes and removing barriers to healthcare access. Improvements to housing and the environment can also mitigate the negative effects of social disadvantage on people's health. ${ }^{9}$ Furthermore, urban policies can help to change aspects of community life, including residents' perceptions, prevailing cultural conceptions, mutual support networks and community life spaces. All these potential impacts on the 'community dimension' of neighbourhoods can modify structural life chances, contributing to shaping health outcomes and their social distribution through the interplay with residents' life choices. ${ }^{10}$ Thus, urban regeneration projects can also be conceived as 'structural transformation agency' interventions to reduce health inequalities, ${ }^{11}$ because they can contribute to increasing the resources that improve material living conditions and provide a wide range of options, enabling people to act in favour of their own health. In a dynamic view, these interventions can promote health-relevant agency processes at the neighbourhood level, which may contribute to modifying the structural conditions shaping health behaviours and beyond.

A growing amount of research demonstrates the existence of these positive effects, though generally at moderate levels. ${ }^{12-15}$ Nevertheless, there is little evidence on whether area-based policies are effective at improving health, and there is a lack of information about the mechanisms through which these interventions could reduce health inequalities. A number of problems arise when evaluating their impact: a lack of theory-based designs, studies using small populations, a lack of comparisons to evaluate programme effectiveness, the quality of available data, etc. ${ }^{12} 1316$ Moreover, most studies using health impact assessment lack theoretical frameworks so as to test specific hypotheses. However, it is recognised that the effects of urban regeneration can also differ depending on the 
health outcome being analysed. ${ }^{17} 18$ Thus, evaluating the potential impact of urban regeneration projects on health inequalities requires theoretical proposals concerning the mechanisms that could explain their impact.

Fundamental Cause Theory (FCT) may provide some of these mechanisms. Its core argument suggests that social inequalities imply an unequal distribution of 'flexible resources' (ie, knowledge, material resources, prestige, social networks, etc) among individuals, groups and social contexts, which would account for the existence and persistence of health inequalities. ${ }^{19-21}$ Studies inspired by FCT have tested how fundamental the role of socioeconomic conditions is in health inequalities, by comparing situations where flexible resources can be deployed with situations in which they cannot, because the capacity to use them or indirectly benefit from them to avoid/minimise the consequences of illness is lacking. ${ }^{22-24}$ In this framework, urban regeneration policies implemented in socioeconomically deprived areas can be conceived as institutional interventions aiming at improving the 'flexible resources' of communities where social problems are more highly concentrated when compared to other areas in the same city. These programmes generally translate into a range of policy actions focusing on housing improvement, educational services, social support and access to healthcare and social services. Following from the theoretical arguments of FCT, such interventions could have some impact on the distribution of health problems in urban settings, as people living in the intervened areas may have some health benefits derived from the use of the resources provided by the interventions. Consequently, area-based interventions, such as urban regeneration programmes, can in fact help improve residents' opportunities to avoid the negative consequences of the disease wherever possible.

Our evaluative proposal is an approach combining the FCT's propositions about 'access to means' and the underlying principle of integral area-based interventions. We aim to test whether urban regeneration programmes effectively contribute to reducing health inequalities. Two hypotheses arise from this framework: first, if urban regeneration policies contribute to reducing health inequality by increasing flexible resources in neighbourhoods, this should be apparent when contrasting the evolution of inequality in preventable mortality against the evolution by causes of death less sensitive to prevention. Second, drawing on urban regeneration literature, we expect that these effects will be more evident when regeneration processes comprise more diverse and integral interventions-in our case, when different programmes overlap in the same area-because it will imply greater allocation of resources and/or different ways to improve the 'access to means'. Accordingly, we postulate that when projects are implemented to intervene on interrelated causes of problems, this will provide a wider range of options to enable people to act more readily in the interest of their own health.

\section{METHODS}

\section{Design, data source and population}

Our study is part of a research project in Spain, entitled Urban Regeneration and Social Cohesion in Andalusia (RUCOSA). We used a quasi-experimental design and a range of quantitative and qualitative techniques to evaluate the effect of urban regeneration policies on several dimensions of community life and life quality. ${ }^{25}$ Specifically, we examined the evolution of inequalities in mortality from preventable and non-preventable causes in neighbourhoods where urban regeneration processes had been implemented ('experimental areas') compared with groups with no such projects ('comparison areas'). The experimental group comprises 59 neighbourhoods in 37 Andalusian municipalities, where urban regeneration projects had been undertaken within the framework of three different programmes: Urban Rehabilitation Areas, implemented from 1999 to 2012 by the Department of Public Works and Housing of the Regional Government of Andalusia (ARB); Areas in Need of Social Transformation, run by the Regional Department of Equality, Health and Welfare (ZNTS) from 2001 to present; and projects included in Initiative URBANA run by the framework of previous European programmes (URBAN) from 2007 to 2014. Although all these projects involve integral processes of neighbourhood intervention, each originates from a different policy framework: public space, habitability, social support to families and communities in re-built houses and buildings (ARB programme); poverty, social exclusion and community life, including interventions from the Andalusian Public Healthcare System aimed at promoting equality of access to healthcare services, combating situations of vulnerability and socio-sanitary exclusion (ZNTS); ${ }^{26}$ and economic competitiveness, social integration, environment and public space (URBAN). The specific actions included in the projects developed in each area have been codified in 14 policy areas in order to compute an index of diversity (see table 1).

The experimental areas were demarcated as aggregations of census tracts based on information provided by the relevant agencies and the documentation for each project. For each experimental area, we selected another geographical area (neighbourhood) in the same city that, based on information provided in the 2001 Spanish Population and Housing Census, had the following characteristics: belonging to the same quintile of the municipal urban inequality indicator, having a population size that would differ by no less and no more than $50 \%$ of the size of the experimental area, and having a similar urban morphology (ie, types of building and urban fabric). In total, the study includes 118 neighbourhoods (see table 2).

Table 1 Description of urban regeneration programmes and budget distribution

\begin{tabular}{|c|c|c|c|c|c|c|}
\hline \multirow[b]{2}{*}{ Programme } & \multirow[b]{2}{*}{ Main policy framework } & \multirow[b]{2}{*}{ Time span } & \multicolumn{3}{|l|}{ Budget } & \multirow{2}{*}{$\begin{array}{l}\text { Policy areas } \\
\text { Diversity } \\
\text { index }(0-1)^{*}\end{array}$} \\
\hline & & & Total (millions euros) & $\begin{array}{l}\text { Average by project } \\
\text { (millions euros) }\end{array}$ & $\begin{array}{l}\text { Average by inhabitant } \\
\text { and year (euros) }\end{array}$ & \\
\hline ARB & Habitability and social integration & 2000-2014 & 2161 & 80.1 & 9452 & 0.66 \\
\hline ZNTS & Poverty and socio-sanitary exclusion & 2001-present & 26.6 & 0.9 & 259 & 0.16 \\
\hline URBAN & $\begin{array}{l}\text { Urban renewal, environment, and } \\
\text { economic competitiveness }\end{array}$ & 2007-2014 & 160 & 10.6 & 1713 & 0.44 \\
\hline
\end{tabular}




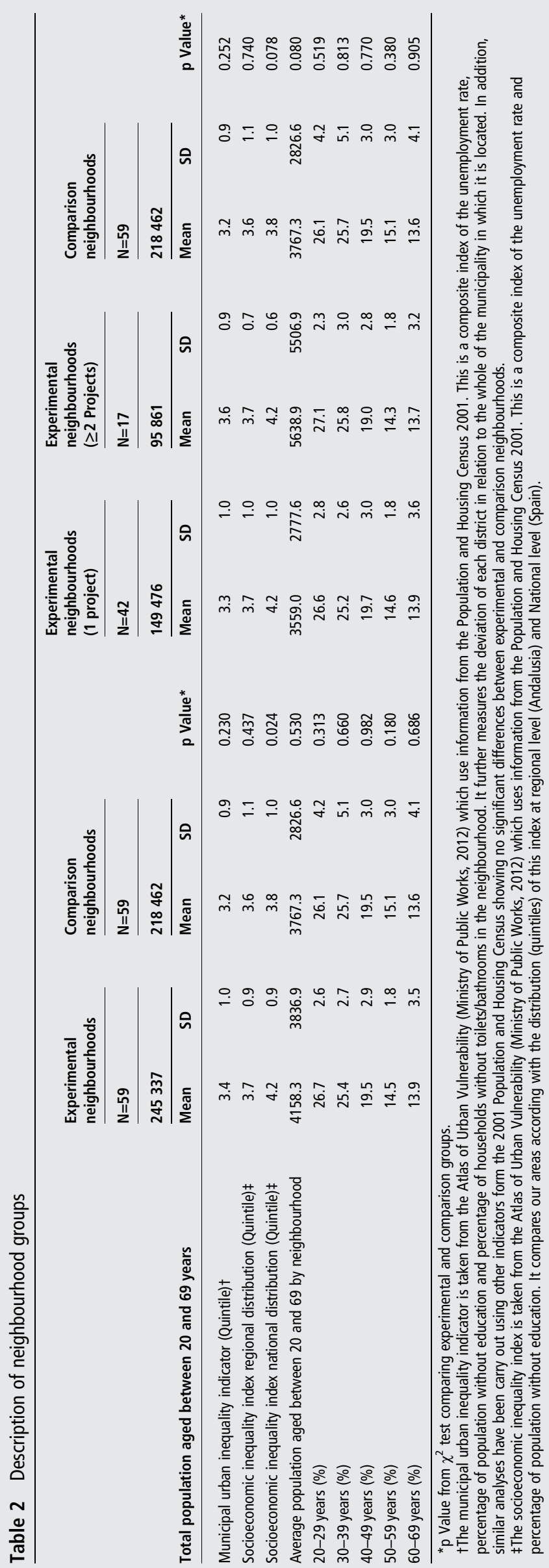

We used data from Longitudinal Statistics on Survival and Longevity in Andalusia (2002-2010, Instituto de Estadística y Cartografía de Andalucia). This allowed us to examine longitudinal information on mortality and its causes through a 9-year follow-up of 7236154 people $(98.3 \%$ of the registered population) living in Andalusia on 1 January 2002. It is based on the information collected in the Census of Population and Housing 2001 and supplemented with that provided by statistical bulletins on death and residential municipal register variations. ${ }^{27}$ Specifically, we focused on the population aged 20 to 69 years living in the experimental and comparison areas in 2001 ( $\mathrm{N}=245337$ and $\mathrm{N}=218$ 462, respectively). Our data offered the basis on which to assess the impact of intervention based on measurements at the beginning of the projects and to compare them with measurements obtained towards the end of the projects-this was used as a proxy of postintervention measures, depending on data availability. Using longitudinal data helped to overcome problems associated with analysing the impact of urban policies based on cross-sectional measurements, when results could have been eventually affected by changes in population resulting from the implementation of the urban regeneration projects themselves. The analysis was thus based on the monitoring of individuals until 2010; specifically, those who had been exposed to the neighbourhood-therefore, to the interventions-from 2001 onwards, excluding the bias that could have been introduced by newcomers in the neighbourhoods after the interventions.

\section{Variables}

Dependent variables: preventable and less-preventable mortality

Although mortality represents an extreme health outcome-it reflects exposure to specific risks and the accumulation of disadvantages through life-it has been previously used in the impact assessment of urban regeneration policies owing to the availability and reliability of data for comparative analysis. ${ }^{12}$ In addition to the overall phenomenon, we also analyse causes of death responsive to prevention and those subject to the poor development of preventive knowledge. In line with our first hypothesis, the impact of urban regeneration programmes should be stronger on the former. Accordingly, our analyses were performed taking into account two dependent variables: mortality from preventable causes and mortality from less-preventable causes, based on the classification proposed by Mackenbach et al. ${ }^{24}$ The online supplementary material provides details of the codes included in each group in accordance with the International Classification of Diseases, ICD-10. Moreover, given the relatively shorter period to assess the impact of area-based interventions on mortality outcomes, we decided to use a third variable called 'preventable-restricted'. With this we aimed at restricting the analysis to the causes of death that could potentially be influenced by the nature of the interventions throughout this period. Thus, this variable included only infectious and parasitic diseases, injuries caused by road traffic accidents, accidental falls and suicide, and avoidable mortality through medical intervention and behavioural change such as hypertensive disease, ischaemic heart disease and cerebrovascular disease.

\section{Independent variables: intervention and integrality}

The type of intervention is our basic independent variable. Of the 59 experimental areas, 42 operated one exclusive project from ARB (16), URBAN (7) or ZNTS (19). A combination of two or more projects from these programmes was implemented in the remaining 17 experimental areas, which, for analytical purposes, resulted in what we termed 'overlap of policies'. The 
combination of interventions included either ARB and ZNTS programmes in 10 areas, or one of them in partnership with the URBAN programme in 7 areas. In these cases, we assumed that the integral nature of the urban regeneration process is greater, as the policy framework of the different programmes allowed complementary interventions. Therefore, our experimental variable differentiates between three types of neighbourhoods: those that had no urban regeneration projects (comparison), those where only one project was implemented (experimental 1 project) and those where two or more projects were simultaneously undertaken (experimental $\geq 2$ Projects). Indeed, the diversity index of the interventions was higher in experimental areas where projects overlapped than it was in experimental areas with only one project (mean 0.68 vs 0.38 , respectively).

\section{Statistical analysis}

We computed relative mortality in each neighbourhood over the periods 2002-2004 and 2008-2010 for all three variables. We estimated standard mortality ratios (SMR) using the indirect standardisation method. The expected cases of mortality were obtained through age-specific standard rates in the whole of Andalusia for the 2002-2010 period. Finally, the SMR for each group of cause, neighbourhood and period were estimated through Poisson regression models. SMR do not allow us to infer mortality rate rises or falls when comparing one period with another, but instead indicate whether the probability of death for a standard resident in an area significantly increases or decreases when compared with the standard population. ${ }^{28}$ This method allows us to assess whether the internal inequalities in terms of mortality in each type of neighbourhood increased or decreased over the periods analysed. For this purpose, we used pairwise comparisons of estimated marginal means between the first and the last 3-year period for each type of neighbourhood. To focus on premature mortality, we analysed the evolution of SMR for the population aged 20-69 years. The analyses are segregated by gender in view of the different health and mortality patterns between men and women

\section{RESULTS}

The descriptive statistics show that our neighbourhood groups have similar characteristics in terms of population size, urban inequality index at a municipal level (by quintiles) and age composition. Their higher SD across all age bands seem to indicate more variability by age composition than in the experimental group, but this had no influence on the results because we use age-standardised mortality ratios. Moreover, the differences according to national distribution of the socioeconomic inequality index indicate that the experimental group is more vulnerable than the comparison group. In this regard, it should be noted that the most of the projects targeted the most deprived urban areas in Andalusia (table 2). When we differentiated between neighbourhoods where only one project was implemented and those where projects overlapped, small differences between the three groups were found (though these are not statistically significant). Thus, even when policies overlapped in strongly deprived areas, no significant differences existed between experimental and comparison neighbourhoods.

As expected, in line with FCT, we did not observe significant differences in mortality due to less preventable causes among the compared periods for each neighbourhoods group (tables 3 and 4). If we examine the evolution of SMR for preventable mortality causes, a significant decrease is apparent in all three types of neighbourhood. Moreover, although the mortality risk due to preventable causes was still higher in experimental areas

Table 3 SMR for men (aged 20-69) from preventable and less-preventable causes of death

\begin{tabular}{|c|c|c|c|c|c|}
\hline \multirow[b]{2}{*}{ Observation units ( 17 by period) } & \multicolumn{2}{|c|}{ Experimental neighbourhoods ( $\geq 2$ project) } & \multirow[b]{2}{*}{ Internal differences in SMRt } & \multirow[b]{2}{*}{ Sig. } & \multirow[b]{2}{*}{$95 \% \mathrm{Cl}$} \\
\hline & $\begin{array}{l}2002-2004 \\
\text { SMR }(95 \% \mathrm{CI})\end{array}$ & $\begin{array}{l}2008-2010 \\
\text { SMR }(95 \% \mathrm{Cl})\end{array}$ & & & \\
\hline Preventable (all) & 1.59 (1.44 to 1.74$)$ & $1.25(1.12$ to 1.38 & -0.34 & *** & -0.54 to -0.14 \\
\hline Preventable-restricted & $1.71(1.51$ to 1.94$)$ & 1.19 (1.03 to 1.38$)$ & -0.52 & $* * *$ & -0.80 to -0.25 \\
\hline Less-preventable & 1.57 (1.29 to 1.85$)$ & 1.34 (1.09 to 1.59$)$ & -0.23 & & -0.60 to 0.15 \\
\hline \multirow[t]{2}{*}{ All-causes } & 1.55 (1.44 to 1.65$)$ & 1.37 (1.27 to 1.48$)$ & -0.17 & * & -0.32 to -0.02 \\
\hline & \multicolumn{2}{|c|}{ Experimental neighbourhoods (1 project) } & & & \\
\hline Observation units ( 42 by period) & $\begin{array}{l}2002-2004 \\
\text { SMR }(95 \% \mathrm{CI})\end{array}$ & $\begin{array}{l}2008-2010 \\
\text { SMR }(95 \% \mathrm{Cl})\end{array}$ & & & \\
\hline Preventable (all) & $1.41(1.30$ to 1.52$)$ & $1.13(1.04$ to 1.22$)$ & -0.28 & $* * *$ & -0.42 to -0.14 \\
\hline Preventable-restricted & $1.44(1.30$ to 1.59$)$ & $1.10(0.98$ to 1.24$)$ & -0.33 & $* * *$ & -0.53 to -0.14 \\
\hline Less-preventable & $1.31(1.12$ to 1.50$)$ & 1.27 (1.09 to 1.46$)$ & -0.03 & & -0.30 to 0.23 \\
\hline \multirow[t]{2}{*}{ All-causes } & 1.35 (1.27 to 1.43$)$ & 1.16 (1.09 to 1.23$)$ & -0.19 & $* * *$ & -0.29 to -0.08 \\
\hline & \multicolumn{2}{|l|}{ Comparison group } & & & \\
\hline Observation units ( 59 by period) & $\begin{array}{l}2002-2004 \\
\text { SMR }(95 \% \mathrm{CI})\end{array}$ & $\begin{array}{l}2008-2010 \\
\text { SMR }(95 \% \mathrm{Cl})\end{array}$ & & & \\
\hline Preventable (all) & $1.02(0.95$ to 1.10$)$ & $0.89(0.82$ to 0.95$)$ & -0.14 & $* * *$ & -0.24 to -0.03 \\
\hline Preventable-restricted & $1.01(0.91$ to 1.12$)$ & $0.89(0.80$ to 1.00$)$ & -0.12 & & -0.26 to 0.02 \\
\hline Less-preventable & $1.10(0.95$ to 1.25$)$ & $0.92(0.79$ to 1.05$)$ & -0.18 & & -0.37 to 0.02 \\
\hline All-causes & $1.06(1.00$ to 1.12$)$ & $0.91(0.86$ to 0.96$)$ & -0.15 & *** & -0.23 to -0.07 \\
\hline
\end{tabular}


than in the whole of Andalusia, its decrease was slightly higher in experimental areas where two or more projects were implemented (SMR difference $=-0.34 ; \mathrm{p}<0.001)$ or where one project was in force $(\mathrm{SMR}$ difference $=-0.28 ; \mathrm{p}<0.001)$ compared to the trend in the comparison group (SMR difference $=$ $-0.14 ; \mathrm{p}<0.001)$. This trend is even clearer for women: the SMR evolution shows how the initial high mortality risk is corrected and disappears in the last 3-year period, in experimental areas with intervention overlap (SMR difference $=-0.51$; $\mathrm{p}<0.001)$ and in those where only one intervention was in force (SMR difference $=-0.23 ; \mathrm{p}<0.05$ ). No significant change is observed in the comparison group (table 4). In the case of men, the difference is stronger when we focus on preventable-restricted causes of death, it includes causes that potentially are closely linked to interventions (SMR difference $=-52 ; \mathrm{p}<0.001$ ).

Figure 1 illustrates the differences in SMR by infectious and parasitic diseases, injuries and avoidable mortality through medical intervention such as hypertensive disease, ischaemic heart disease and cerebrovascular disease (preventable-restricted group). The excess of mortality by those causes is significantly reduced in the intervened areas. From 2002-2004 to 20082010, SMR in neighbourhoods where two projects have been in force decreased significantly for both sexes: from 1.71 (CI 1.44 to 1.74 ) to 1.19 (CI 1.03 to 1.38 ) in men and from 1.70 (CI 1.34 to 2.06 ) to 1.20 (CI 0.90 to 1.50 ). According to the information provided by the $\mathrm{CI}$, the inequality in mortality for these preventable causes of death disappears for women in 20082010. Conversely, no significant changes were found in the comparison group.

\section{DISCUSSION}

The analysis shows in the first place that the decrease in excess mortality in intervened areas is mainly the result of reduced deaths from preventable causes, which is consistent with the theoretical frame of FCT. The FCT scheme suggests four 'metamechanism' to differentiate between ways in which a set of specific mechanisms can emerge and contribute to reproducing the relationship between socioeconomic conditions and health. These four meta-mechanisms are: access to means, spill-overs, socially structured individual health preferences and institutional agency. ${ }^{29}$ The first one refers to systematic differences according to socioeconomic conditions in the access to means at individual and contextual level. This is the main assumption of our research, aligned with the underlying argument that urban regeneration policies can contribute to increasing the flexible resources promoting health-relevant agency. Urban regeneration policies can enhance access to a wide range of material and nonmaterial resources, so that people living in the target areas improve their education and employment situation, their social relations, the access to public and health services and so on. 93031

Different pathways through which these policies can have an effect on health inequity have been identified in urban renewal literature: ${ }^{32}$ (1) enhancing access to certain material and nonmaterial resources that contribute to mitigating unequal distribution across different social groups, such as gender, ethnicity and socioeconomic status; (2) directly improving neighbourhoods' physical and social environment, that is, ensuring a fairer distribution of those community factors which can promote health (health amenities) or transforming those which can be harmful, that is, unprotected roads which can cause accidents, poor water facilities failing to provide drinkable water, badly insulated buildings which can increase risk of respiratory diseases, degraded social spaces which increase psycho-social unrest and do not facilitate social interaction, etc; and finally (3), improving opportunities and action capacity in affected communities, that

Table 4 SMR for women (aged 20-69) from more-preventable and less-preventable causes of death

\begin{tabular}{|c|c|c|c|c|c|}
\hline \multirow[b]{2}{*}{ Observation units ( 17 by period) } & \multicolumn{2}{|c|}{ Experimental neighbourhoods ( $\geq 2$ project) } & \multirow[b]{2}{*}{ Internal differences in SMRt } & \multirow[b]{2}{*}{ Sig. } & \multirow[b]{2}{*}{ IC $95 \%$} \\
\hline & $\begin{array}{l}2002-2004 \\
\text { SMR }(95 \% \mathrm{CI})\end{array}$ & $\begin{array}{l}2008-2010 \\
\text { SMR }(95 \% \mathrm{CI})\end{array}$ & & & \\
\hline Preventable (all) & 1.52 (1.27 to 1.76$)$ & $1.00(0.81$ to 1.20$)$ & -0.51 & ** & -0.82 to -0.20 \\
\hline Preventable-restricted & 1.70 (1.34 to 2.06$)$ & $1.20(0.90$ to 1.50$)$ & -0.50 & * & -0.97 to -0.03 \\
\hline Less-preventable & $1.19(0.82$ to 1.56$)$ & $1.33(0.94$ to 1.72$)$ & 0.14 & & -0.40 to 0.68 \\
\hline \multirow[t]{3}{*}{ All-causes } & 1.51 (1.35 to 1.67$)$ & 1.15 (1.01 to 1.29$)$ & -0.36 & $* * *$ & -0.57 to -0.15 \\
\hline & \multicolumn{2}{|c|}{ Experimental neighbourhoods (1 project) } & & & \\
\hline & $\begin{array}{l}2002-2004 \\
\text { SMR }(95 \% \mathrm{CI})\end{array}$ & $\begin{array}{l}2008-2010 \\
\text { SMR }(95 \% \mathrm{CI})\end{array}$ & & & \\
\hline Preventable (all) & 1.28 (1.11 to 1.45$)$ & $1.05(0.90$ to 1.20$)$ & -0.23 & * & -0.46 to -0.01 \\
\hline Preventable-restricted & 1.42 (1.17 to 1.66$)$ & 1.10 (0.89 to 1.32$)$ & -0.32 & & -0.64 to 0.01 \\
\hline Less-preventable & $0.95(0.70$ to 1.20$)$ & $1.06(0.80$ to 1.32$)$ & 0.10 & & -0.26 to 0.46 \\
\hline \multirow[t]{3}{*}{ All-causes } & $1.23(1.12$ to 1.33$)$ & $1.10(1.00$ to 1.20$)$ & -0.13 & & -0.28 to 0.02 \\
\hline & \multicolumn{2}{|l|}{ Comparison group } & & & \\
\hline & $\begin{array}{l}2002-2004 \\
\text { SMR }(95 \% \mathrm{CI})\end{array}$ & $\begin{array}{l}2008-2010 \\
\text { SMR }(95 \% \mathrm{Cl})\end{array}$ & & & \\
\hline Preventable (all) & $0.90(0.78$ to 1.01$)$ & $0.86(0.75$ to 0.97$)$ & -0.04 & & -0.20 to 0.12 \\
\hline Preventable-restricted & $0.95(0.78$ to 1.12$)$ & $0.73(0.59$ to 0.88$)$ & -0.22 & & -0.44 to 0.01 \\
\hline Less-preventable & $0.93(0.72$ to 1.14$)$ & $1.10(0.88$ to 1.32$)$ & 0.17 & & -0.13 to 0.47 \\
\hline All-causes & 0.92 (0.84 to 0.99$)$ & 0.95 (0.87 to 1.03$)$ & 0.03 & & -0.08 to 0.14 \\
\hline
\end{tabular}



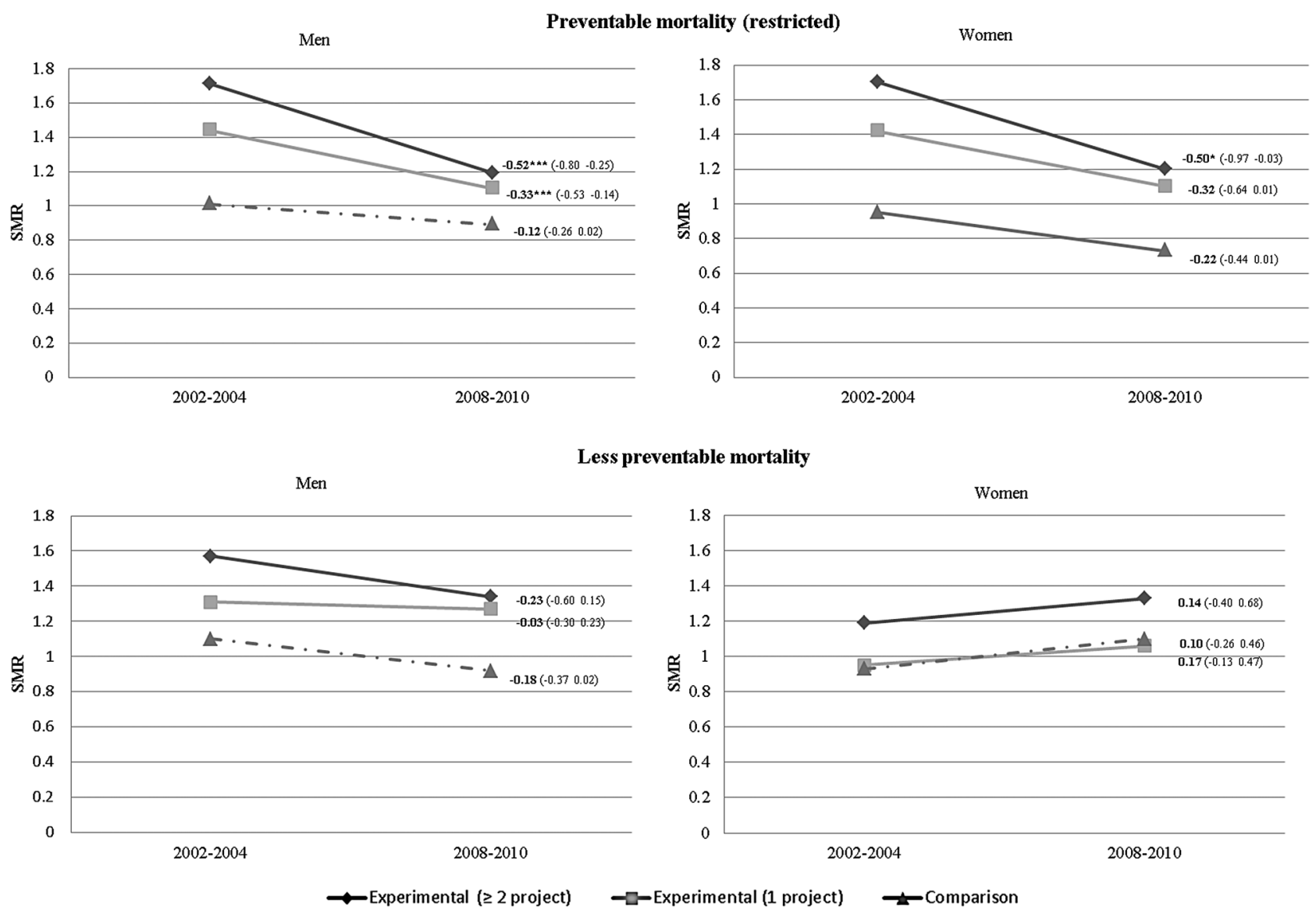

Figure 1 Trend in internal mortality disparities by the type of neighbourhoods: preventable (restricted) and less preventable causes of death.

is, improving urban transport and accessibility to promote better social integration of vulnerable communities across the city - which would mitigate residential segregation and fight stigmatisation-improving work skills through training plans, promoting participation and raising awareness about social problems, working on integration between neighbours, a sense of belonging and collective effectiveness, etc.

In the studied areas, the improvement of substandard houses, buildings and environment could reduce mortality excess due to infectious disease and injuries. In a cross-sectional survey carried out in the framework of the RUCOSA project in 2015 in neighbourhoods from big cities in Andalusia, $\sim 8 \%$ of the respondents who lived in intervened areas for more than 14 years confirmed that their house was renovated with the support of public policies. This proportion rose to $12 \%$ in neighbourhoods from areas with project overlap. In the case of buildings, these proportions were $14.8 \%$ and $21.1 \%$, respectively. On the basis of census data (2001 vs 2011), we can also observe improvements in the proportion of homes without barriers (see online supplementary material).

The mechanism called Institutional Agency can also play a relevant role here. This meta-mechanism highlights the active and dynamic functions of institutions. ${ }^{29}$ For example, institutions such as the healthcare system, social services and the education system can also contribute to preserving (or mitigating) health inequalities through the way they interact with or treat individuals depending on their socioeconomic circumstances, gender, ethnicity, age, etc. In this regard, there have been actions developed in the framework of the ZNTS programme, such as the creation of a primary care professional network to promote collaborative work and to guide healthcare towards vulnerable families living in areas with special need of social transformation. Specifically, these actions have been oriented to improve access to healthcare and continuity of care in those areas. $^{26}{ }^{33}$ The improvement of healthcare access in those areas could be related to the decrease of mortality excess due to hypertensive disease, ischaemic heart disease and cerebrovascular disease. In addition, according to the RUCOSA survey, more than $30 \%$ of residents from intervened areas declared that public services in the neighbourhood, like school, primary healthcare centre, social services, public transport and cultural-leisure time services, have improved over the last 10 years. In this line, and using census data, we have also identified an increase in the percentage of young people achieving compulsory education in the intervened areas between 2001 and 2011 (see online supplementary material). Therefore, our findings are in line with previous research showing the positive impact of urban regeneration on health and its social determinants, ${ }^{14} \quad{ }^{15} \quad 34-40$ yet introducing a specific analytical link in order to explain this impact (ie, improvement of 'access to means' and the reduction of preventable mortality).

Second, our analysis shows that the urban regeneration policies being studied seem to contribute to reducing health inequity when the intervention is more integral, that is, when it involves combined interventions from different policy frameworks. Specifically, combined actions imply more-integral interventions, because the development of policy measures in more and diverse policy areas, as well as different types of intervention strategies-for instance, combining actions for individuals 
and families, and for the urban environment-could promote more reliable improvements to the level and character of deprivation in intervened areas-for instance, combining housing and public space improvements with social support and healthcare access and continuity of care. In this vein, previous research shows that the mortality risk is influenced by relative changes in the level of deprivation of neighbourhoods. ${ }^{41} 42$

Third, this analysis also shows that potential effects are even more evident for women than for men when we focus on our extended group of preventable causes. Two complementary explanations can be suggested: women are more exposed to neighbourhood life and thus to the improvements derived from urban regeneration projects, whether direct (housing improvement and accessibility to guidance and health services) or indirect (urban context improvements). ${ }^{43}$ Alternatively, this may reflect the effects of the 'substitution of resources' hypothesis, which states that the beneficial effects of the resources contributed by these types of policies are stronger for women than for men, because the result being assessed (in this case inequality in mortality) depends to a greater extent on these policies in view of the lack of other resources. ${ }^{44}$

Finally, it is necessary to bear in mind that the differences in health inequality reduction could also reflect differences in health-related behaviours according to gender, as well as biological differences, life conditions at an early stage, differences in illness processes in adulthood and susceptibility to mortality risk. This has important implications for the planning of urban regeneration processes given that in addition to generally helping to overcome health inequity, by incorporating a gender perspective in their design, they may contribute useful tools for addressing gender health inequality. ${ }^{45}$

Our results suggest that urban regeneration processes can contribute to reducing health inequalities by acting as a 'structural transformation agency' through promoting the improvement of neighbourhood conditions and trying to address the unequal social distribution of resources relevant to health. Urban regeneration projects can also be conceived as community interventions, oriented at promoting the role of individuals as active agents that are able to produce structural changes at local levels and thus enhance the health of deprived communities (in the medium to long term). ${ }^{11}$ Area-based interventions imply changes in structural life chances, which modify and improve residents' life choices according to their access to more and diverse flexible resources. Our analysis also suggests that more-integral interventions-namely, more diverse flexible resources at the individual and the community level-imply a greater reduction in mortality risk in experimental overlap neighbourhoods, and that a similar effect appears at higher exposure to the neighbourhood structure opportunity, as the gender difference in our analysis shows.

\section{CONCLUSION}

Our study contributes to the growing literature on urban renewal and health equity, by using a quasi-experimental design and data on the follow-up of the population in intervened and comparison areas. This approach minimises problems related to changes in the social composition of neighbourhoods when attempting to assess the impact of urban regeneration programmes. It also opens up the possibility to integrate contributions from health sociology in the health impact assessment of area-based interventions. Specifically, the study has taken into account potential variations in the effectiveness of flexible resources according to gender and the nature of the health outcome being investigated. This approach could evidently benefit from integrating in the future at least two different points of view. First, detailed analyses are required considering other variables representing less-extreme results than mortality in order to more robustly verify the existence of these effects. As mentioned above, relevant literature indicates that the impact of urban regeneration processes can vary depending on the health results examined. Our study adds that this impact should be more evident regarding preventable diseases. Yet, we were unable to split preventable mortality into more specific causes of death, which undoubtedly could have contributed to test specific pathways among the interventions and mortality. We focused on groups of causes of death with enough events in the intersection among type of areas and periods for both sexes in order to maintain the stability of SMR.

Second, our study allows us only to verify that area regeneration projects have potential effects on residents' health at an aggregate level of analysis: neighbourhoods. Therefore, it would be beneficial to carry out different types of analyses to investigate urban regeneration effects in greater detail, not solely on preventable mortality but instead on quality of life and morbidity. More relevant in our view, another methodological approach might enable the unravelling of the underlying mechanisms of the effects of interventions on health in specific areas combining contextual and residents' information. Particularly contributing would be the relative importance of direct and indirect effects of urban regeneration projects (ie, What is the importance of being or not being the beneficiary of a specific measure in an intervened area?), the level of exposure to the projects (ie, Which specific groups are affected and to what extent is level of exposure important in terms of life in the neighbourhood?) and the type of exposure according to the resources acquired during the intervention process (ie, Which flexible resources derived from this type of policy are the most relevant and what type of measures have residents benefitted from?).

If we view neighbourhoods as opportunity structures that condition the distribution of material resources, knowledge, participation in cultural life, social relations and the support networks among individuals and families living in these areas, then urban regeneration policies imply interventions that can have an effect on the processes through which these resources are socially distributed. ${ }^{7}$ In line with our aim of integrating FCT postulates with the assessment of the impact of urban regeneration policies, this could imply that area-based initiatives improve the opportunity structure by providing different types of flexible resources to residents, which may mediate the welldocumented inverse relationship between socioeconomic status and mortality risk.

\section{What is already known on this subject}

- The built environment can influence the health of residents and its social distribution.

- Neighbourhoods constitute spatially defined distribution networks, through which resources are accessible for producing good health.

- Urban regeneration policies can have positive effects on health, though generally at moderate levels. 


\section{What this study adds}

- This theory-driven study provides evidence concerning the effect of urban regeneration processes on health inequality using a quasi-experimental design. Urban regeneration policies seem to contribute to reducing excessive preventable mortality when interventions are more comprehensive in nature.

- It opens up the possibility to integrate contributions from health sociology in the health impact assessment of area-based interventions.

- Area-based initiatives can improve the opportunity structure providing flexible resources to residents, which may mediate the inverse relationship between socioeconomic status and health.

Acknowledgements This research is part of RUCOSA project (Urban Regeneration and Social Cohesion in Andalusia: towards an evaluative analysis) which has been funded by the I+D framework of the Department of Housing-Government of Andalusia and the ERDF-European Union. The authors thank the staff and researchers at the Consejería de Fomento y Vivienda of the Junta de Andalucía, and of all its agencies for their work and professionalism in supporting the development of this project. The authors further wish to thank the Instituto de Estadística y Cartografía de Andalucía (IECA), specifically for giving access to the Longitudinal Statistics on Survival and Longevity in Andalusia (2002-2010), especially to Dr. Francisco J. Viciana for his invaluable help and suggestions regarding the data set. Finally the authors wish to thank Professor Dr. Piet Bracke (Gent University) for his helpful comments and Dr. Ricardo A. Ayala Valenzuela from his invaluable helps with language editing and remarks.

Contributors Both authors have contributed to formulated the research questions and hypotheses, worked with different data sets to get valid information to perform the analysis, as well as carried out the statistical analysis and interpret the results. They made substantial contributions to the elaboration of theoretical framework and the discussion. They have revised critically the manuscript. Both authors have read and approved the final manuscript.

Funding The research was funded by the ERDF-European Union, in the framework of the I+D+I programme of the Department of Public Works and HousingGovernment of Andalusia ('Programa Operativo FEDER de Andalucía 2007-2013').

Competing interests None declared.

Provenance and peer review Not commissioned; externally peer reviewed.

\section{REFERENCES}

1 Roberts $P$. The evolution, definition and purpose of urban regeneration. In: Roberts P, Sykes H, eds. Urban regeneration: a handbook. London: Sage Publications Ltd, 2000:9-36.

2 MacGregor C. Urban regeneration as a public health intervention. J Soc Interv: Theory Pract 2010;19:38-51.

3 Van Gent WPC, Musterd S, Ostendorf W. Disentangling neighborhood problems: area-based interventions in Western European cities. Urban Res Pract 2009;2:53-67.

4 Carmon N. Neighborhood regeneration: the state of the art. J Plann Educ Res 1997:17:131-44.

5 Andersen HT, van Kempe R. New trends in urban policies in Europe: evidence from the Netherlands and Denmark. Cities 2003:20:77-86.

6 Macintyre S, Ellaway A, Cummins S. Place effects on health: how can we conceptualise, operationalise and measure them? Soc Sci Med 2002;55:125-39.

7 Bernard $\mathrm{P}$, Charafeddine R, Frohlich $\mathrm{KL}$, et al. Health inequalities and place: a theoretical conception of neighbourhood. Soc Sci Med 2007;65:1839-52.

8 Pearce J. An environmental justice framework for understanding neighbourhood inequalities in health and well-being. In: Manley D, van Ham M, Bailey N, et al. eds. Neighbourhood effects or neighbourhood based problems? London: Springer, 2013:89-112.

9 Mehdipanah R, Manzano A, Borrell C, et al. Exploring complex causal pathways between urban renewal, health and health inequality using a theory-driven realist approach. Soc Sci Med 2015;124:266-74.

10 Cockerham WC. Health lifestyle theory and the convergence of agency and structure. J Health Soc Behav 2005;46:51-67.
11 Abel T, Frohlich KL. Capitals and capabilities: linking structure and agency to reduce health inequalities. Soc Sci Med 2012;74:236-44.

12 Thomson $\mathrm{H}$, Atkinson $\mathrm{R}$, Petticrew $\mathrm{M}$, et al. Do urban regeneration programmes improve public health and reduce health inequalities? A synthesis of the evidence from UK policy and practice (1080-2004). J Epidemiol Community Health 2006:60:108-15.

13 Thomson $\mathrm{H}$. A dose of realism for healthy urban policy: lesson from area-based initiative in the UK. J Epidemiol Community Health 2008:62:932-6.

14 Thomson $\mathrm{H}$, Thomas S, Sellstrom E, et al. The health impacts of housing improvement: a systematic review of intervention studies from 1887 to 2007 Am J Public Health 2009;99(Suppl 3):S681-92.

15 Mehdipanah R, Rodríguez-Sanz M, Malmusi D, et al. The effects of an urban renewal project on health and health inequalities: a quasi-experimental study in Barcelona. J Epidemiol Community Health 2014;68:811-7.

16 Rossi PH. Evaluating community development programs: problems and prospects. In: Fergusson RF, Dickens WT, eds. Urban problems and community development. Washington DC: The Brookings Institution, 1999:521-69.

17 Jacobs DE, Brown MJ, Baeder A, et al. A systematic review of housing interventions and health: introduction, methods, and summary findings. J Public Health Manag Pract 2010;16:S5-10.

18 Egan M, Lawson L, Kearns A, et al. Neigbourhood demolition, relocation and health. A qualitative longitudinal study of housing-led urban regeneration in Glasgow, UK. Health Place 2015;33:101-8.

19 Link BG, Phelan J. Social conditions as fundamental causes of disease. J Health Soc Behav 1995;35:80-94.

20 Phelan JC, Link BG. Controlling disease and creating disparities: a fundamental cause perspective. J Gerontol B Psychol Sci Soc Sci 2015;60(Spec No 2):S27-33.

21 Phelan JC, Link BG, Tehranifar P. Social conditions as fundamental causes of health inequalities theory, evidence, and policy implications. J Health Soc Behav 2010;51 (Suppl):S28-40.

22 Phelan JC, Link BG, Diez-Roux A, et al. "Fundamental causes" of social inequalities in mortality: a test of the theory. J Health Soc Behav 2004;45:265-85.

23 Rubin MS, Clouston S, Link BG. A fundamental cause approach to the study of disparities in lung cancer and pancreatic cancer mortality in the United States. Soc Sci Med 2014;100:54-61.

24 Mackenbach JP, Kulhánová I, Bopp $\mathrm{M}$, et al. Variations in the relation between education and cause-specific mortality in 19 European populations: a test of the "fundamental causes" theory of social inequalities in health. Soc Sci Med 2015:127:51-62.

25 This project was funded by the I+D framework of the Department of Housing-Government of Andalucía and the ERDF-European Union. http://www. centrosociologia.geographica.gs/en/

26 Daponte A, Bernal M, Bolívar J, et al. Criteria for implementing interventions to reduce health inequalities in primary care settings in European regions. Eur J Public Health 2014;24:980-90

27 IECA: Longitudinal Statistics on Survival and Longevity in Andalusia, 2002-2010. http://www.juntadeandalucia.es/institutodeestadisticaycartografia./longevidad/ index-en.htm (accessed 24 Nov 2015).

28 Bartley M. Figuring out health inequality. In: Bartley M, ed. Health inequality: an introduction to theories, concepts and methods. Cambridge: Polity Press, 2004:35-62.

29 Freese J, Lutfey K. Fundamental causality: challenges of an animating concept for medical sociology. In: Pescosolido BA, Martin JK, McLeod J, et al. Handbook of the sociology of health, illness, and healing. New York: Springer, 2011:67-81.

30 Borrell $C$, Pons-Vigués $M$, Morrison J, et al. Factors and processes influencing health inequalities in urban areas. J Epidemiol Community Health 2013;67:389-91. doi:10.1136/jech-2012-202014.

31 Kjellstrom T, Friel S, Dixon J, et al. Urban environmental health hazards and health equity. J Urban Health 2007:84:86-97.

32 Northridge ME, Freeman L. Urban planning and health equity. J Urban Health 2011:88:582-97.

33 García-Sánchez I, Tirado MC. Quality in and equality of access to healthcare services. Country report for Spain. Granada, Spain: Andalusian School of Public Health for the European Commission, 2008. http://www.ehma.org/files/healthquest_ spain_en.pdf (accessed 06 Jun 2016).

34 Cambridge Policy Consultants. An evaluation of the new life for urban Scotland initiative in Castlemilk, Ferguslie Park, Wester Hailes and Whitfield. Edinburgh, UK: Scottish Executive, Central Research Unit, 1999.

35 Droomers M, Harting J, Jongeneel-Grimen B, et al. Area-based interventions to ameliorate deprived Dutch neighborhoods in practice: does the Dutch district approach address the social determinants of health to such an extent that future health impacts may be expected?. Prev Med 2014;61:122-7.

36 Stafford M, Badland H, Nazroo J, et al. Evaluating the health inequalities impact of area-based initiatives across the socioeconomic spectrum: a controlled intervention study of the New Deal for Communities, 2002-2008. J Epidemiol Community Health 2014;68:979-86

37 Kearns A, Mason P. Regeneration, relocation and health behaviours in deprived communities. Health Place 2015;32:43-58. 
38 Mehdipanah R, Malmusi D, Muntaner C, et al. An evaluation of an urban renewal program and its effects on neighborhood residents' overall wellbeing using concept mapping. Health Place 2013;23:9-17.

39 Renalds A, Smith TH, Hale PJ. A systematic review of built environment and health Fam Community Health 2010;33:68-78.

40 Giles-Corti B, Bull F, Knuiman M, et al. The influence of urban design on neighbourhood walking following residential relocation: longitudinal results from the RESIDE study. Soc Sci Med 2013;77:20-30.

41 Boyle $P$, Norman P, Rees P. Changing places. Do changes in the relative deprivation of areas influence limiting long-term illness and mortality among non-migrant people living in non-deprived households? Soc Sci Med 2004;58:2459-71.

42 Ben-Shlomo $Y$, White IR, Marmot M. Does the variation in the socioeconomic characteristics of an area affect mortality? BMJ 1996:312:1013-14.

43 Stafford M, Cummins S, Macintyre S, et al. Gender differences in the associations between health and neighbourhood environment. Soc Sci Med 2005:60:1681-92.

44 Ross CE, Mirowsky J. Gender and the health benefits of education. Sociol Q 2010:51:1-19.

45 Burgess $G$. Planning and the Gender Equality Duty — why does gender matter? People Place Policy Online 2008;2:112-21. 